\title{
Santa María de la Sierra: una curiosa opción ornamental dentro del Císter castellanoleonés
}

\author{
M. Aitana Monge ZaPATA \\ Universidad Complutense de Madrid. Departamento de Historia del Arte I (Medieval) / \\ Fundación Universitaria José Luis de Oriol-Catalina de Urquijo
}

\begin{abstract}
RESUMEN
A pesar de las conocidas reticencias del Císter a la representación figurativa dentro de sus monasterios, en algunos de ellos la opción ornamental de tipo vegetal no fue tan preferente como se cree, ni tan respetada como cabría esperar. Una de esas excepciones que confirman la regla del aniconismo cisterciense es la modestísima iglesia de Santa María de la Sierra-Sotosalbos (Collado Hermoso, Segovia). Este discreto templo abacial custodia entre sus ruinas -y entre sus capiteles vegetales- un pequeño muestrario zoológico de aves, leones y liebres, capaz de enriquecer significativamente el repertorio empleado por esta Orden religiosa, demostrando la importancia de la itinerancia de modelos y la influencia de las opciones del románico geográficamente circundante e inmediatamente precedente -o incluso contemporáneo-, que fue más fuerte de lo que se piensa, desmontando la teoría infundada -y respaldada por muchos autores- de la existencia del llamado "estilo cisterciense".
\end{abstract}

Palabras clave: Císter; Segovia; capiteles; ornamentación animalística (aves, leones y liebres); talleres escultóricos.

\section{Santa María de la Sierra: an interesting ornamental option within the Cistercian art of Castile-Leon}

\begin{abstract}
Despite the well known Cistercian reluctance to figurative representation in their monasteries, the vegetal ornamental patterns precept was not as preferred as thought nor it was as honoured as expected in some of them. One of the exceptions that prove the rule to Cistercian aniconism is found in the very humble church of Santa María de la Sierra-Sotosalbos (Collado Hermoso, Segovia); this discrete abbatial temple holds in its ruins -and among its vegetal capitals- a small zoological collection of birds, lions and hares capable of significantly enriching the repertoire used by this religious order, demonstrating that the importance of ornamental models itinerancy and the influence of the geographically nearby and historically precedent Romanic options - even the contemporary Romanic- was stronger than thought, taking to pieces the unfounded theory -backed by many authors- of the existence of the so called "Cistercian Style".
\end{abstract}

Keywords: Cistercian Order; Segovia; capitals; animalistic ornamentation (birds, lions and hares); sculpture workshops. 


\section{Introducción}

"Todos nuestros monasterios se fundarán en honor de la Reina del Cielo y de la tierra. Ninguno se edificará en ciudades, aldeas o castillos. No se enviará a una nueva fundación a un nuevo Abad sin al menos doce monjes [...] ni sin haberse construido antes estas dependencias: oratorio, refectorio, dormitorio, hospedería y portería; de modo que al llegar a aquel lugar puedan enseguida servir a Dios y vivir según la Regla".

Exordio de Císter, "Sobre la construcción de abadías", cap. 5.

A pesar de las modestísimas ruinas que han llegado hasta nosotros, las fuentes históricas conservadas evidencian el interesante pasado del monasterio de Santa María de la Sierra, reclamando la atención de numerosos investigadores que se han sentido atraídos por la paradójica historia de una de las cuatro abadías españolas afiliadas directamente por la casa madre de Cîteaux, que se extinguió tras una vida menesterosa, efímera y opaca. Resulta chocante la ubicación de este cenobio segoviano, ya que "entre las gargantas de Somosierra y Guadarrama, se levanta un cerro [...] y en su falda la ermita de la Virgen de la Sierra". Es cierto que las casas de los monjes blancos se enclavaban por lo general en lo profundo de los valles o en lugares alejados del tránsito de viandantes, pero este monasterio no fue una fundación ex novo, sino una afiliación tardía partiendo de una comunidad previa de origen benedictino, pudiendo resultar curioso que la Orden cisterciense estuviese dispuesta a asentarse en una vía de comunicación como era el camino que iba de Sotosalbos a Pedraza ${ }^{2}$, aunque por la escasa importancia de esta ruta no resultaba del todo inadecuado dicho emplazamiento.

La primera noticia documental alusiva a Santa María y Santiago de la Sierra ${ }^{3}$ se remonta al año 1133; se trata de la dotación inicial que el obispo cluniacense Pedro de $\operatorname{Agen}^{4}$ (1110-1149) hizo a un grupo de religiosos benedictinos -encabezados

1 VILLANUEVA, Ricardo, "La Virgen de la Sierra", en La Ilustración española y americana, año XVI, $\mathrm{n}^{\circ}$ XXVI, 1872, p. 411.

2 Hoereditatis, quae est iuxta montem inter Pironem, et Lacerteram: et ab ipsis montibus usque ad illam viam, quae ducit a Sotos Alvos ad Pedrazam: COLMENARES, Diego de, Historia de la insigne ciudad de Segovia y compendio de las historias de Castilla, I, Segovia, 1969 (1637), p. 236.

3 Carta de hereditate Sanctae Mariae Beati Jacobi de Serra: Ibidem, p. 236. La advocación combinada Santa María-Santiago con el tiempo desaparecerá de la documentación a favor de la mariana, adecuándose plenamente a las premisas del Císter. Cfr., ABAD CASTRO, $\mathrm{M}^{\mathrm{a}}$ Concepción y SENRA GABRIEL Y GALÁN, José Luis, "Santa María de la Sierra", en Segovia cisterciense, Segovia, 1991, p. 142.

4 Ego Petrus Dei gratia, etsi indignus sanctae Segoviensis Ecclesiae humilis minister, una cum omnium eiusdem Ecclesiae Canonicorum consenso, nullo cogente, sed spontanea voluntate dono et concedo in elemosinam tertiam partem illius haereditatem... Vid. MARTÍN POSTIGO, $\mathrm{M}^{\mathrm{a}}$ de la Soterraña, 'Santa María de Cardaba', Priorato de Arlanza y Granja de Sacramenia, Valladolid, 1979, documento V, p. 115. Algunos historiadores fechan la cesión del Concejo en 1116 [cfr. CONTRERAS Y LÓPEZ DE AYALA, Juan de (Marqués de Lozoya), "Una excursión por tierras de Segovia", en Boletín de la Sociedad Española de excursiones, XXIV, 1916, p. 148], otros la retrasan a 1123 quizá confundiéndola con la donación que ese mismo año hizo la reina doña Urraca del lugar llamado Collado Hermoso [cfr. TORRES BALBÁS, Leopoldo, "El Monasterio de Nuestra Señora de la Sierra”, en Peñalara. Revista ilustrada de alpinismo, año IX, n 106, 1922, p. 208], 
por Guillelmo [...] Monacho supredictae Eclessiae $-^{5}$, de un tercio de la heredad de Sotosalbos-Collado Hermoso ${ }^{6}$, lugar en que ya debía existir un eremitorio con su correspondiente capilla ${ }^{7}$.

A pesar de haber condicionado el desarrollo de Santa María de la Sierra la jurisdicción territorial ejercida tanto por el obispo como por el cabildo de Segovia, lo cierto es que don Pedro de Agen nunca dejó de velar por sus hijos espirituales del monasterio de la Sierra, pero sus esfuerzos fueron vanos, pues la joven abadía apenas podría hacer frente a los gastos derivados del afianzamiento de la nueva casa.

Probablemente fue consecuencia de la patente pobreza en que estaban sumidos los monjes benedictinos de Santa María de la Sierra, la decisión que el obispo Gonzalo M. (1192-1211) tomó para "corregir excesos en la comunidad de Sotos Albos, regida por el abad Blas, a la que promete no obligarles a cambiar de Orden, pero teniendo sobre ella las facultades de un abad cisterciense respecto a los otros abades inferiores" $"$. Este acuerdo se firmó el año $1201^{10}$, haciendo uso de la potestad fundacional que le correspondía como obispo de Segovia. La decadencia del monasterio vino de la mano de la pobreza económica, y la reorientación de la vida comunitaria por parte del obispo obedeció a su interés por la incorporación a la reforma de los monjes blancos (a pesar de especificarse en el documento justo lo contrario) asentada en la infundada idea de que el Císter era el remedio para acabar con todos los males monásticos. El cambio de observancia tuvo lugar no mucho tiempo después de este acuerdo, contando con la aprobación de la comunidad. La afiliación se produjo directamente a través de monjes venidos desde Cîteaux, en una fecha que tuvo que acontecer antes de 1219, momento en que se emitió la escritura en la que ya se explicita la pertenencia a la nueva Orden. Tradicionalmente

pero lo cierto es que el privilegio no está fechado, "y no pudo ser otorgado antes de 1120 en que fue ordenado el obispo don Pedro": MARTÍN POSTIGO, Ma de la Soterraña, "El Monasterio de 'Santa María de la Sierra' (Sotosalbos)", en Cistercium, no 163, 1982, p. 248.

5 COLMENARES, Diego de (1969), op. cit., p. 237.

6 Dono tibi aquesta haereditat erma [vid. MARTÍN POSTIGO, Ma de la Soterraña (1982), op cit., p. 253]. La repoblación de las tierras al sur del Duero hicieron posible que Sotosalbos estuviese habitado en marzo de 1139, y Collado Hermoso fuese poblado a partir del mes de abril de ese mismo año. Ibídem, pp. 243 y 252 .

Ecclesia Beatae et gloriosae semperque Virginis Mariae, santique Iacobi Apostoli: quae iuxta iam dictos terminos aedificata est: et Fratribus ibidem sub Regula Beatissimi Benedicto Deo servientibus ut prennifer habeant: COLMENARES, Diego de (1969), op. cit., p. 237.

8 El cabildo pobló Sotosalbos y Pelayos, y el obispo Pedro de Agen Santo Domingo de Pirón y Collado Hermoso, además asentó el palacio episcopal en las proximidades del cenobio serrano [cfr. COLMENARES, Diego de (1969), op. cit., p. 219]. Los vecinos de estas poblaciones debían vasallaje a la sede segoviana, privando de ingresos al cercano monasterio de Santa María de la Sierra [cfr.: MARTÍN POSTIGO, M ${ }^{a}$ de la Soterraña (1979), op. cit., p. 90].

9 TORRES BALBÁS, Leopoldo, "La iglesia del Monasterio de Nuestra Señora de la Sierra", en Archivo Español de Arte, $\mathrm{n}^{\circ}$ 18, 1945 p. 74. Incluso gozaba el obispo del privilegio de nombrar a los abades.

10 Cfr. COLMENARES, Diego de (1969), op. cit., p. 324. 
los tratadistas del Císter han aceptado el año 1212 para el ingreso de Santa María de la Sierra en la familia cisterciense.

El templo consta de tres naves -la central carente de luces directas- de diferente anchura, altura y longitud ${ }^{11}$, e igual número de ábsides semicirculares de diferente profundidad -precedidos de espacios rectos-, con sus respectivas cinco crujías ${ }^{12}$.

Sobre gruesos pilares cruciformes montados en zócalos circulares con columnas embebidas en sus frentes, apean arcos fajones y formeros de perfil apuntado y potente dobladura, que atestiguan -al igual que los restos de la nave de la epístolaque la cubrición del templo se solucionó con bóvedas de cañón apuntado para las naves y los tramos preabsidales, y posiblemente cuartos de esfera para las cuencas.

Pilares, columnas, impostas, cantoneras, contrafuertes, arcos, guarniciones de puertas y ventanas se realizaron con una bella piedra caliza dorada bien escuadrada, mientras que los muros perimetrales, ábsides y bóvedas fueron construidos con mampuesto trabado con mortero de cal.

Lo más señalado del templo se concentra en el hastial de Poniente, destacando la horizontalidad del conjunto, sólo mitigada por la pareja de contrafuertes -con talud a media altura y remate empiñonado- que flanquea el cuerpo central al tiempo que traduce la compartimentación tripartita interna. Amenizan los lienzos correspondientes a las naves laterales sendos óculos tetralobulados insertos en una sucesión de molduras abocinadas. El eje longitudinal presenta un acceso formado por una puerta moldurada que se decora con dientes de sierra y puntas de clavo, y el hueco de un rosetón ${ }^{13}$ que sigue abrigado por un contundente arco de descarga ligeramente apuntado.

El muro meridional está recortado en la actualidad por un par de vanos de medio punto de diferente luz, así como por varios accesos. La puerta más occidental es un simple recorte murario de perfil agudo, que comunicaría la cilla con el primer tramo de la iglesia. Coincidiendo con el arco fajón más occidental, se dispuso la puerta (¿de legos?), con una sucesión de molduras de medio punto que reposan en el arranque-remate borgoñón ${ }^{14}$. Otra puerta -en la actualidad condenada-, que

11 "La nave central, de 6,90 de anchura, elevábase algo más que las laterales, de ancho desigual -5,10 y 4,60- [...] Longitud total interior, 40,30 metros. Ancho total interior, 19,20”: TORRES BALBÁS, Leopoldo (1945), op. cit., pp. 75-76.

12 En la actualidad, la cabecera está casi del todo arrasada, no quedando en algunas zonas ni las evidencias de los cimientos. De igual forma, la mayor parte de las cubiertas del templo se ha venido abajo, así como importantes fragmentos del muro.

13 Una de las descripciones de la rosa hecha cuando aún se conservaba parte de la tracería nos dice que poseía "divisiones radiales y [...] dos series de rondeles lobulados": CONTRERAS Y LÓPEZ DE AYALA, Juan de (1916), op. cit., p. 150. Existe una imagen de hacia 1870, perteneciente al fondo Ruiz Vernacci, en que se puede ver el aspecto del rosetón [vid. TORRES BALBÁS, Leopoldo, (1945), op. cit.].

14 "Sus arcos no llegaban a la imposta, consiguiéndose la transición entre aquéllas y el plano vertical del paramento por medio de pequeñas superficies cilíndricas, acusadas en los frentes por semicircunferencias, sistema borgoñón muy difundido por el sudeste de Francia”: Ibidem, p. 80, n. 1. 
arranca por debajo del nivel del suelo, hizo pensar si no sería el acceso -desde el claustro- a la cripta ${ }^{15}$ a que hizo referencia el autor del tumbo del monasterio de Sacramenia: "en medio del coro, abajo, había una cueva que le cogía todo él y el presbiterio hasta el altar mayor de bóveda que llamaban de San Bartolomé, que está derrotada al presente" ${ }^{\prime 6}$. Se conservan evidencias de una cuarta puerta meridional o de monjes, arruinada hacia 1925, dispuesta a la altura de la segunda crujía del templo, de la que sólo se conserva parte de la jamba izquierda.

Las obras debieron comenzarse con la incorporación de Santa María de la Sierra a la familia cisterciense, ya que "no cabe pensar que los trabajos de edificación del monasterio comenzaran antes de 1219, dada la escasísima dotación con que contaba la comunidad antes de esta fecha. A lo largo del siglo XIII continuarían los trabajos, que no habían de concluirse hasta bien entrado el siglo XIV"17.

\section{Santa María de la Sierra y lo peculiar de su repertorio ornamental}

"Y además, entre los hermanos que leen en los claustros, ¿qué hace la ridícula monstruosidad, una cierta admirable belleza deforme y una deformidad bella? ¿Qué hacen, pues, los monos, inmundos, qué los fieros leones, qué los monstruosos centauros, qué los semihombres, qué los rayados tigres, qué los soldados luchadores, qué los cazadores soplando sus cuernos? [...] En una palabra, tanta y tan admirable variedad de formas diversas aparece por todas partes, que agrada más leer en los mármoles que en los códices, y ocupar todo el día admirando estas cosas singulares, que meditando la ley de Dios..."

Bernardo de Claraval, Apología a Guillermo de Saint Thierry, cap. XII, 29.

Para el santo abad claravalense, la verdadera belleza (pulchritudo) de las construcciones arquitectónicas no estaba en el aditamento ornamental (venustas) como consideraban muchos de los teóricos medievales-, sino en la simplificación voluntaria, en la desnudez de volúmenes y en la coherencia estructural ${ }^{18}$. Bernardo de Claraval, llevado por un pragmatismo docente que debió aprender del mismo san Gregorio, se negó a tolerar cualquier elemento de ornato que no contribuyese a la mejora espiritual de los que lo contemplasen, pensando especialmente en los

\footnotetext{
15 "Pudimos advertir cómo a varios metros de profundidad, ocultos bajo la tierra, aparecían sendos arcos, de lo que fácilmente suponemos sería la cripta”: GÓMEZ SANTOS, Antonio, "Santa María de Párraces, Nuestra Señora de la Sierra y San Pedro de los Picos”, en Estudios Segovianos, nos. 68-69, 1971, p. 309.

16 Tumbo de Sacramenia, año 1757. Cfr. MARTín POSTIGO, Ma de la Soterraña (1982), op cit., p. 269.

17 Ibídem, p. 83.

18 Otros pensadores de la Edad Media también enarbolan estas ideas defendiendo lo que se ha denominado "la estética de la austeridad" dentro de los claustros consagrados a la vida contemplativa: "Los edificios de los frailes no deben ser excesivos, sino humildes; no voluptuosos, sino honestos. La piedra es útil en la estructura, pero ¿de qué le aprovecha el cincelado? [...] Leamos el Génesis en el libro, no en los muros”: Vid. FOUILLOI, Hugo de, "De claustro animae II", en JAQUES PI, Jêssica, La estética del románico y el gótico, Madrid, 2003, p. 294.
} 
simplices et devoti ${ }^{19}$, aunque su pertinaz insistencia a este respecto también incluía de forma clara y decidida a los monjes que debían dedicarse a la meditación de la Palabra de Dios y a la santificación de sus almas, y no a la contemplación de las representaciones que ocupaban los claustros, o al deleite sensorial a través de la belleza de los elementos suntuosos ${ }^{20}$.

En su Apología a Guillermo de Saint-Thierry, san Bernardo hace referencia a tres motivos iconográficos bien definidos (seres monstruosos, animales salvajes y hombres dedicados a actividades mundanas), de los cuales sólo en el segundo de los casos -el de los animales "naturales"- encontramos reflejo en nuestra abacial segoviana, aunque todo apunta a que también hubiese en este templo algún testimonio de los combates o psicomaquias ${ }^{21}$. Santa María de la Sierra dispone entre sus treinta y nueve capiteles conservados, de un pequeño repertorio de siete de temática figurativa, siendo seis de ellos de tipo animalístico, que serán el objeto preferente de este estudio.

Resulta sorprendente encontrar en una iglesia bernarda tan modesta como la de Sierra un repertorio ornamental tan variado, aunque puede ser aún más curioso descubrir tal profusión de capiteles con representación de animales en armoniosa convivencia con otros tipos aceptados y difundidos por la Orden como son las hojas lanceoladas, los crochets y las hojas compuestas ${ }^{22}$. Entiéndase por "hojas lanceoladas" la opción más generalizada dentro del Císter, en la que quedan incluidos todos los capiteles decorados con grandes hojas lisas que tienden a la forma de punta de lanza (de ahí su nombre) ya sean festoneadas o sencillas, y sea cual sea la opción elegida para sus remates (complementadas con distintos elementos, con otras hojas compuestas antepuestas, marcadas o vueltas en diferentes soluciones). Los crochets son elementos decorativos más avanzados -cronológicamente hablando-, en que su acabamiento ganchudo le asemeja a la labor de punto que da nombre a este motivo escultórico. Y, respondiendo a pautas más naturalistas, están los capiteles resueltos mediante "hojas compuestas" o lobuladas, ya propias de cronologías góticas.

19 Cfr. BOTO VARELA, Gerardo, Ornamento sin delito. Los seres imaginarios del claustro de Silos y sus ecos en la escultura románica peninsular, Abadía de Silos, 2000, p. 50.

20 "Pero nosotros que nos hemos separado del pueblo, que por Cristo hemos abandonado todo lo precioso y agradable del mundo, que hemos considerado como basura, para ganar a Cristo, todo lo que luce bello, halaga con sonidos, huele suavemente, sabe con dulzura, agrada al tacto, en fin, todos los deleites corporales, ¿con estas cosas, pregunto, pretendemos excitar la devoción?”: Vid. CLARAVAL, Bernardo de, "Apología ad Guilhelmum abbatem", en JAQUES PI, Jêssica (2003), op. cit., p. 284.

${ }^{21}$ Un excursionista en los albores del siglo XX enumera algunos elementos ornamentales de la iglesia de Santa María de la Sierra que, lamentablemente, no han pervivido hasta nuestros días: "Esculpidos en metopas, sófitos (sic) y canecillos se admiran, en perfecto estado de conservación, mascarones humanos, expresión cada uno de un sentido diverso; hombres de armas con espadas y paveses, en actitud bélica; cigüeñas y otras aves, de perfil y de frente; cuadrúpedos, monstruos, florones, etc...": ESCOLAR, V., "Excursión a Sotosalbos. Descubrimiento artístico", en Boletín de la Sociedad Española de Excursiones, VIII, n 90-92, 1900, p. 172.

22 Para aproximarnos a los motivos de exorno más utilizados en las construcciones cistercienses vid. MONGE ZAPATA, M. Aitana, "Santa María de Palazuelos y las posibilidades de la hoja lanceolada", en Anales de Historia del Arte, Volumen Extraordinario, octubre 2010, p. 212, fig. 1 y p. 213, n. 53. 
Repasaremos ahora con detalle todos y cada uno de los capiteles de esta iglesia monástica, a fin de familiarizarnos con su repertorio ornamental y centrarnos en el animalístico.

Tal y como puede apreciarse en la planta cromática ${ }^{23}$ (fig. 1), en primera línea de imposta -representados mediante colores sólidos- existen tres capiteles de hojas lanceoladas ${ }^{24}$, otros tantos de crochets $^{25}$, cinco de hojas compuestas ${ }^{26}$ y siete

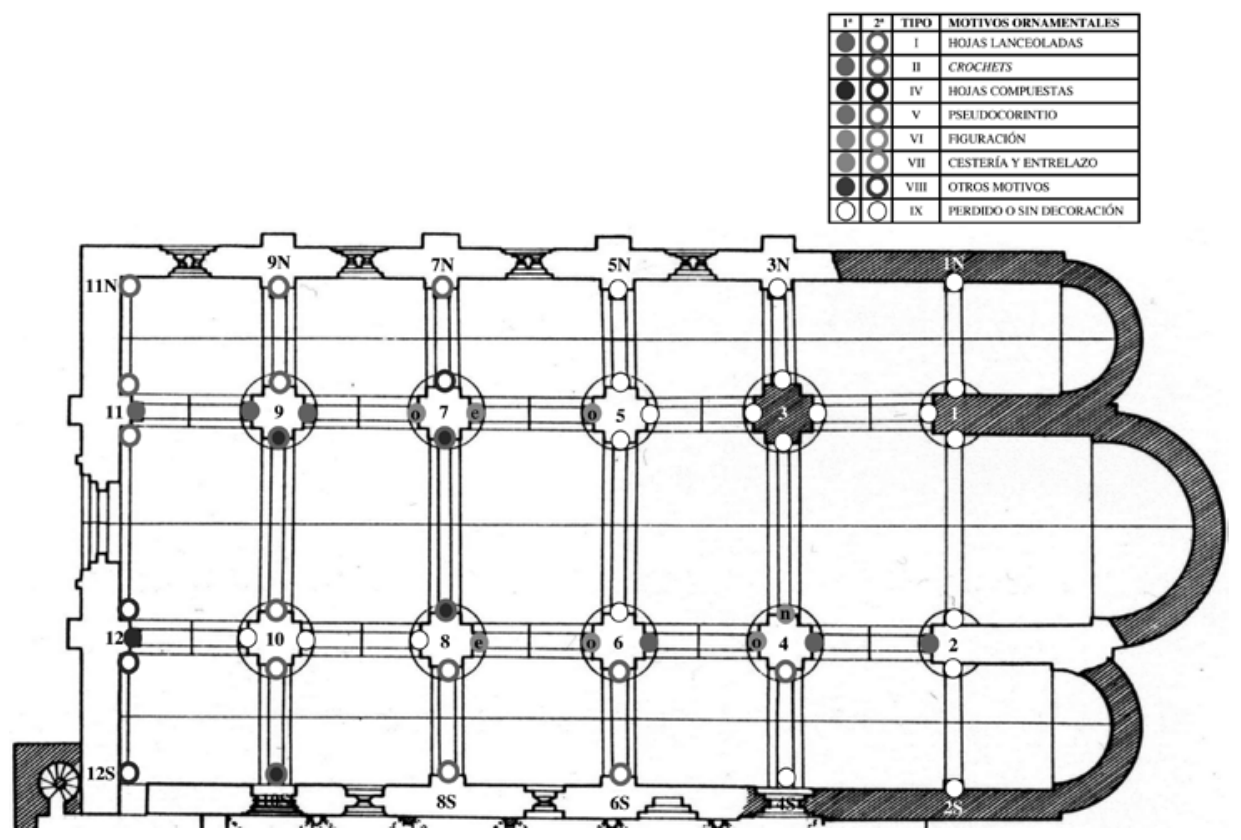

Fig. 1. Planta cromática de la iglesia con localización de capiteles en primera y segunda imposta, Santa María de la Sierra, Collado Hermoso (Segovia), 1220-1244 [planta según L. Torres Balbás].

figurativos ${ }^{27}$, de lo que se puede deducir fácilmente que ésta es la opción predilecta en la primera altura de su alzado. En segunda línea de imposta-coincidiendo con

23 Mantengo uno de los instrumentos metodológicos creados y empleados -la planta cromática- para la elaboración del trabajo de investigación defendido en 2008 ["El repertorio ornamental medieval de las iglesias cistercienses del entorno del Duero", bajo la dirección del Dr. Javier Martínez de Aguirre, para la obtención de la suficiencia investigadora en el Departamento de Historia del Arte I (Medieval) de la Universidad Complutense de Madrid] y para la tesis doctoral en curso, por presentar de forma gráfica y clara la plasmación del cromograma en primera y segunda imposta de forma simultánea.

24 Elementos 2oeste, 4este y 6este.

25 Elementos 9este, 9oeste y 11 este.

26 Elementos 7sur, 8norte, 9sur, 10S y 12 este.

27 Elementos 4norte, 4oeste, 5oeste, 6oeste, 7este, 7oeste y 8este. 
el arranque de las bóvedas, y representado en planta mediante un arete o bordura de color- encontramos seis capiteles de la tipología de hojas lanceoladas ${ }^{28}$, diez de crochets $^{29}$, cuatro de hojas compuestas ${ }^{30} \mathrm{y}$ ninguno de figuración.
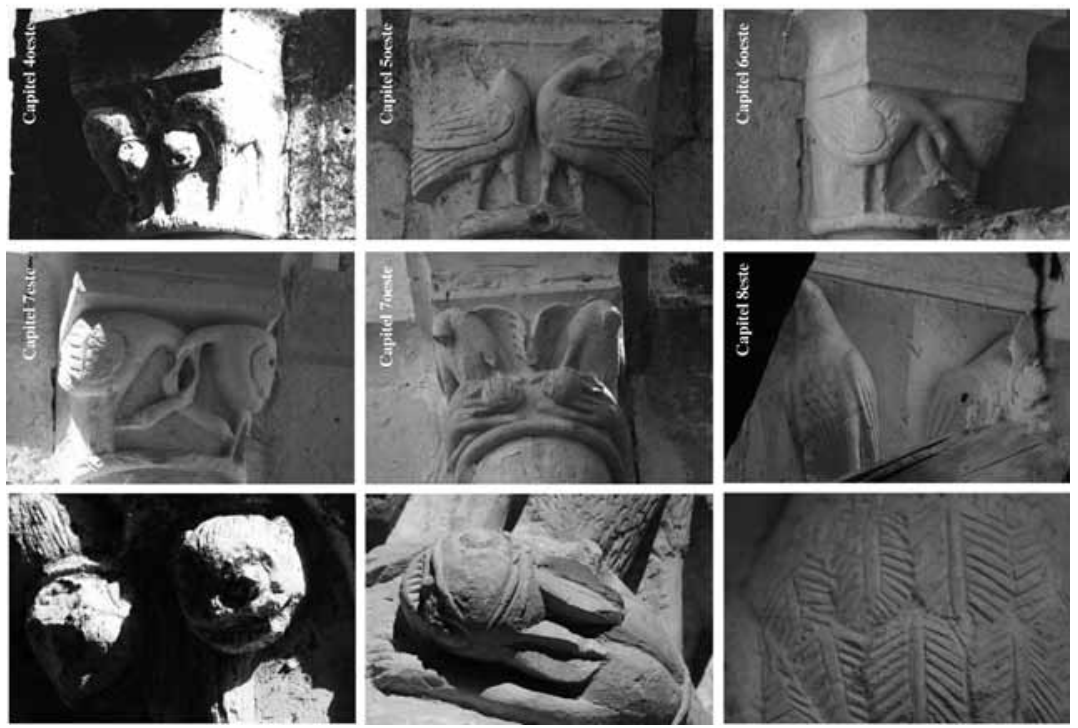

Fig. 2. Capiteles animalísticos de la iglesia abacial de Santa María de la Sierra.

Como decía más arriba, lo excepcional de Santa María de la Sierra está en su repertorio zoológico, y no en su decoración vegetal -tan frecuente dentro de las casas del Císter-, de ahí que en las líneas que siguen pasemos a analizar los seis capiteles animalísticos ${ }^{31}$ que exornan esta iglesia monástica en su primera línea de imposta (fig. 2).

En el capitel 4oeste han sido representados dos cuadrúpedos afrontados y simétricamente dispuestos, trabados mediante un lazo que se anuda en el eje por encima de sus cabezas. Por sus afiladas garras, lo amenazante de sus dentaduras, las comedidas melenas distribuidas en mechones, y sus colas remetidas entre las patas traseras para tapar discretamente el sexo, parece lógico pensar que se trate de leones de estilizada anatomía, dentro de lo que muchos autores denominan "leones

28 Elementos 4sur, 6sur, 8sur, 8S, 10 norte y 10 sur.

29 Elementos $6 \mathrm{~S}, 7 \mathrm{~N}, 7$ sur, $9 \mathrm{~N}, 9$ norte, 9 sur, $10 \mathrm{~S}, 11 \mathrm{~N}, 11$ norte y 11 sur.

30 Elementos 7 norte, 12 norte, 12 sur y $12 \mathrm{~S}$.

31 En la planta cromática los motivos zoológicos se muestran, además de mediante un pequeño círculo de color rosa, con una letra minúscula negra que hace alusión a la orientación del elemento con respecto a su posición en el pilar (n: norte; s: sur; e: este; o: oeste). La ménsula 4n, a pesar de formar parte en el cromograma del grupo "figuración", no será analizada aquí por quedar fuera del subgrupo "animales" al ser una testa de hombre que, por permanecer a la intemperie, está muy maltrecha. 
patilargos".

El capitel 5oeste presenta una pareja de aves afrontadas y dispuestas simétricamente en torno a un eje vertical imaginario, oponiendo sus pechos pero volviendo hacia atrás las cabezas en un bello gesto de rechazo mutuo. Su potente anatomía se concreta en unas fuertes patas de dedos extremadamente largos que reposan grácilmente sobre el collarino del capitel, cuerpos muy compactos de amplia caja torácica con ordenadas alas de someras plumas, y cuellos robustos que rematan en unas cabezas de las que apenas quedan restos pero en las que se puede intuir la potencia del pico.

En el inacabado capitel 6oeste se representa otra pareja de volátiles dispuestas en los ángulos de la cesta. Las aves entrelazan sus desarrollados cuellos mientras cada cual se pica decididamente la caña de una de las patas, que está ligeramente adelantada respecto a la otra. A causa de la erosión e interrupción de los trabajos de talla, sólo uno de los pájaros presenta detalladas las plumas que cubren la parte alta de su cuerpo, en un trazado preciso aunque no demasiado volumétrico

El capitel 7este se resuelve mediante otra pareja de aves llevadas a los ángulos de la cesta también representadas en vista lateral, con cuellos entrecruzados y picándose -respectivamente- su pata adelantada. Tal y como sucedía en el capitel 6oeste, la labor de tallado de las plumas sólo se hizo efectiva en uno de los animales, y por su mejor estado de conservación se nos permite apreciar la largura de sus dedos y la tipología de los picos -cortos y fuertes- evidenciando que se trata de aves anatómicamente idénticas a las del capitel anterior.

Sin duda, el capitel 7oeste es el más sorprendente y atractivo del conjunto zoológico serrano. Distribuidas en dos registros superpuestos aparecen dos parejas de animales, aves en el piso superior y pequeños cuadrúpedos en el inferior. Atendiendo primero a los animales voladores, por su pose majestuosa - a pesar de aparecer mutilados a la altura de las cabezas y parcialmente en sus extremidades superiores-, y por la forma decidida de apresar a los animales del registro bajo - con patas de dedos flexibles y desproporcionadamente largos-, podríamos concretar que se trata de aves rapaces en plena maniobra de inmovilización de una presa. Los mamíferos (limitándonos a la mera descripción) son animales de largos miembros que presentan una forzada posición ventral que permite apreciar perfectamente la columna vertebral acabada en una pequeña cola que, escueta, se vuelve sobre el lomo. En lo tocante a la cabeza, se ajusta perfectamente a la forma de una esfera, sobresaliendo de su volumen sólo dos lanceoladas orejas dispuestas en paralelo y tendidas hacia atrás, un par de redondos ojos saltones y una poblada y amenazante dentición serrada.

Cerrando este muestrario animalístico está el capitel 8este en el que de nuevo una pareja de aves es la protagonista. En este caso los pájaros no se dispusieron de forma afrontada entre ellas, sino frontal con respecto al capitel y en los ángulos de su cesta. Anatómicamente nos encontramos con otra pareja de pájaros de cuello fuerte y recias patas con garras asidas al collarino del capitel. También en esta 
ocasión las cabezas se han perdido, a pesar de la precaución del escultor, que dispuso los gruesos cuellos ascendiendo por la arista de la cesta. Destaca este capitel cercenado por la preciosista labor de talla del plumaje del pecho de las aves (foto inferior derecha, figura 2).

La torpeza de los artífices encargados de la labra de estos capiteles, deja vía libre a la imaginación en lo que se refiere a la interpretación de los seres en ellos representados; por ese motivo no existe unanimidad a la hora de poner nombre a las aves emparejadas, ni a los felinos anudados, ni a los cuadrúpedos sumisos. Los distintos autores definen a las primeras como "cigüeñas y otras aves"32, "pareja de palomas" "aves" ${ }^{34} \mathrm{o}$ "aves, algunas de cuellos entrelazados" ${ }^{35}$. Tampoco se ponen de acuerdo al precisar qué se representa en el que es el capitel más curioso de la abacial, si "trasgos y arpías"36 o "rapaces apresando liebres" ${ }^{37}$. En el único caso que parece alcanzarse el consenso entre los investigadores que han prestado atención a los capiteles zoomórficos de Sierra, es en el de los cuadrúpedos que tienen por "felinos de lomos erizados" 38 o simplemente por "representación de leones"39. Personalmente -y a pesar de no alcanzar los artistas de estos capiteles el verismo zoológico- me decanto por identificar las aves de Santa María de la Sierra con aves de rapiña ${ }^{40}$, los cuadrúpedos con liebres ${ }^{41}$, y los felinos con leones (aunque por carecer de la soberbia melena característica se asemejen más a las hembras de su especie que a los machos).

\section{Leones, rapaces y liebres: origen y cuestionamiento de una iconografía}

"El león, de varias formas, domina a muchos animales; por eso es rey el león. Escuchad ahora sus propiedades: tiene la expresión ardiente, el cuello grueso y con melena;

32 ESCOLAR, V. (1900), op. cit., p. 172.

${ }^{33}$ SANTAMARÍA, Juan Manuel, "Las iglesias románicas de la Villa y Tierra de Pedraza", en Estudios Segovianos, t. XXIII, nº 68-69, 1971, p. 190.

${ }^{34}$ ABAD CASTRO, M ${ }^{a}$ Concepción y SENRA GABRIEL Y GALÁN, José Luis (1991), op. cit., p. 147.

${ }_{35}$ HERNANDO GARRIDO, José Luis, "Monasterio de Santa María de la Sierra o de Sotosalbos", en Enciclopedia del Románico en Castilla y León, Segovia, vol. I, Aguilar de Campoo, 2007, p. 556.

36 ABAD CASTRO, M ${ }^{a}$ Concepción y SENRA GABRIEL Y GALÁN, José Luis (1991), op. cit., p. 149.

${ }^{37}$ HERNANDO GARRIDO, José Luis (2007), op. cit., p. 556. Este autor parece parafrasear lo que otros historiadores han descrito en publicaciones anteriores, al mezclar los temas representados hasta resultar más temáticas animalísticas que capiteles zoológicos hay: "con capiteles más antiguos para la nave central, donde aparecen aves, algunas de cuellos entrelazados, rapaces apresando liebres, trasgos y cuadrúpedos afrontados de cuellos anudados".

38 SANTAMARÍA, Juan Manuel (1971), op. cit., p. 190.

39 ABAD CASTRO, M ${ }^{a}$ Concepción y SENRA GABRIEL Y GALÁN, José Luis (1991), op. cit., p. 148.

40 Agradezco el asesoramiento ornitológico prestado por la doctora Ruiz Montejo -reputada estudiosa del bestiario claustral silense y del románico segoviano- a la hora de identificar las aves representadas en Santa María de la Sierra.

${ }^{41}$ La extraña forma de la liebre y su peculiar anatomía - patas delanteras y traseras colocadas hacia adelante, orejas abatidas, pequeña cola sobre la espalda y cabeza chata de grandes ojos- se encuentra de forma casi idéntica en un canecillo de la iglesia de Nuestra Señora de la Asunción de Losana de Pirón (foto 36, figura 5). 
el pecho, por delante, es cuadrado y agresivo; los cuartos traseros, delgados; tiene una gran cola, y las patas lisas y ágiles junto a los pies; los pies, gruesos y cortados, con uñas largas y curvadas".

Philippe de Thaün, Le Bestiaire, I. 5, vv. 26-33.

Intentar buscar un sentido simbólico a los capiteles resueltos con motivos vegetales de la abacial de Santa María de la Sierra resultaría tan cuestionable como hacer lo mismo con los de temática zoológica, dado que no se tiene ninguna seguridad de que fuese esa la pretensión de los artífices intervinientes en esta empresa ${ }^{42}$.

Resulta muy tentador buscar interpretaciones iconográficas y programáticas al conjunto ornamental del monasterio que nos ocupa, pero el vacío documental existente a este respecto y la falta de noticias que puedan inducirnos a pensar que se quisiese ofrecer un discurso moralizante a través del exorno de esta iglesia, nos hace andar con pies de plomo por el campo de la suposición de la iconografía tallada en sus capiteles y ménsulas, ya que pudieran haberse utilizado aquí algunos motivos ornamentales independientemente del significado que en otras partes pudiesen tener ${ }^{43}$.

¿Cómo podemos interpretar, entonces, la conocidísima reacción de Bernardo de Claraval en su Apología ad Guillelmum y el rechazo sistemático hacia cualquier tipo de representación figurativa en los ámbitos monásticos, si en iglesias abaciales cistercienses como la de Santa María de la Sierra se llegaron incluso a contrariar las recomendaciones del que es uno de los referentes morales de la Orden? El auge de la disputa ornamental que enfrentó a cluniacenses y cistercienses tocó su cota más alta entre los años 1130 y 1140, aunque los argumentos de la tesis bernardina no debieron alcanzar con la misma fuerza a todas las casas de monjes blancos, puesto que no fueron acogidas con la misma intensidad en todas ellas ya que incluso en algunos casos se ignoraron por completo ${ }^{44}$.

Cabe pensar que una fundación tan modesta, tardía y periférica como la de Santa María de la Sierra se posicionase bastante al margen de esta polémica que fue

42 Estudiosos afamados como Mâle y Dehio desconfiaron del significado que otros investigadores quisieron atribuir a la fauna y a la flora representadas en las obras medievales, de no existir constatación documental que la pudiera certificar; por este motivo no se debía buscar más que un sentido decorativo a esos motivos ornamentales. Cfr. BOTO VARELA, Gerardo (2000), op. cit., p. 49.

43 "El artista medieval no suele inventar los motivos iconográficos que esculpe, talla y pinta [...] sino que normalmente recurre a modelos ya creados para plasmar sus representaciones": MARTÍNEZ DE LAGOS, Eukene, "Un tema iconográfico procedente del arte oriental antiguo en la escultura medieval alavesa: el águila con presa", en Sancho el Sabio: revista de cultura e investigación vasca, nº 7, 1997, p. 318.

44 "San Bernardo estaba convencido de que la acumulación de pinturas u obras de orfebrería (puede suponerse que también quedarían incluidas las representaciones escultóricas talladas en la piedra) era incompatible con la atención al desahuciado [...] y que su perversa exposición en los santuarios monásticos no pretendía sino atraer a los laicos y, con ellos, a sus óbolos. La presencia de estos visitantes seculares en medio de hombres dedicados a la vida contemplativa desazonaba al Doctor Melifluo. Pero más aún le irritaba la actitud de aquellos monjes que, lejos de transmitir consuelo espiritual, únicamente estaban interesados en engrosar las arcas de sus cenobios con las limosnas de los pobres": BOTO VARELA, Gerardo (2000), op. cit., p. 50. 
perdiendo vigor a lo largo de los años, quedando más bajo el influjo de las corrientes artísticas locales que de las altas disputas teológicas mantenidas en Francia más de un siglo antes. Por este motivo, son representados sin ningún tipo de pudor diversos animales en algunos capiteles de esta iglesia monástica bernarda, mediante los cuales no se tiene la seguridad de que los artífices quisiesen ser fieles a especies zoológicas concretas, ni de que intentasen dotarlas de algún tipo de sentido simbólico o de que lograsen reproducir la anatomía real de estas especies puesto que, debido a su escasa capacidad artística, se propició la materialización de animales ambiguos de los que desconocemos si persiguieron una intención y un significado concreto, y de los que en algunos casos ni tenemos la certeza de su identificación.

Partiendo de la suposición de que los capiteles de Sierra exhiben leones, rapaces y liebres, podría decirse algo sobre el origen y significado de cada una de estas especies, aunque -como se apuntó más arriba- todo debe valorarse con cautela y tenerse como hipótesis por no existir evidencias de que se pretendiesen representar aquí por su significado o simbolismo ${ }^{45}$.

Supuestamente en el capitel 4oeste se representó una pareja de leones. El león es un animal asociado a la divinidad desde los cultos paganos de Europa, África y Asia ${ }^{46}$. Como símbolo dual simultanea sentidos positivos y negativos, cristológicos y diabólicos ${ }^{47}$. En el mundo cristiano se convirtió en emblema e imagen de la resurrección, de la muerte hipostática de Cristo, de su doble naturaleza, de la ciencia divina y de la vigilancia permanente ${ }^{48}$. Este animal gozó de buena consideración entre los monjes, ya que fue humanizado por Eliano ${ }^{49}$ y encumbrado por san Pedro Damiano al decir de él que era digno de imitación por su permanente vigilancia y por procurar el alimento a sus progenitores ancianos y desvalidos - de lo que se hizo eco la Regla de san Benito- ${ }^{50}$, aunque también se pretende alertar a los monjes de la

45 Como dijo Lucas de Tuy: "ciertas imágenes son pintadas y esculpidas en la Casa de Dios para la protección de los fieles, para la doctrina, para el ejemplo y [...] otras son solamente para la decoración [...]. Hay en las iglesias figuras pintadas de animales, de pájaros, de serpientes y otras criaturas que no son nada más que para el ornato y la belleza": MARTÍNEZ DE LAGOS, Eukene (1997), op. cit., p. 314.

${ }^{46}$ Egipcios, ammonitas, sirios, tibetanos, griegos, persas, asirios... adoptaron la imagen del león para representar los distintos atributos de la divinidad. Cfr. CHARBONNEAU-LASSAY, Louis, El bestiario de Cristo. El simbolismo animal en la Antigüedad y la Edad Media, vol. 1, Barcelona, 1996, pp. 35-36.

47 “Cachorro de león, Judá” (Gn. 49, 9). "Ha triunfado el León de la tribu de Judá” (Ap. 5, 5). "Marcharán tras Yahvé, él rugirá como león” (Os. 11, 10). "Pisarás sobre el león y la víbora” (Sl. 91, 13). "Sálvame de las fauces del león" (S1. 21, 22). "Como león tritura todos mis huesos” (Is. 38, 13). "Sed sobrios y velad. Vuestro adversario, el Diablo, ronda como león rugiente, buscando a quien devorar” (1 Pe. 5, 8).

48 Apunta el Fisiólogo que el león borraba con la cola sus huellas para que el cazador no siguiese su rastro, y que con Cristo murió en la cruz su naturaleza humana aunque la divina veló junto al Padre, y fue resucitado de entre los muertos al tercer día. Cfr. DOCAMPO ÁLVAREZ, Pilar y VILLAR VIDAL, José Antonio, "El Fisiólogo latino: versión B. 2. Traducción y comentarios", en Revista de literatura medieval, $\mathrm{n}^{\circ}$ 15/2, 2003, pp. 107-108. Vid. CHARBONNEAU-LASSAY, Louis (1996), op. cit., pp.37-47.

49 Vid. ELIANO, Claudio, De Natura Animalium, Parissis, A. Firmin Didot ed., 1858.

50 "Aunque la misma naturaleza humana mueva a ser misericordioso con estas dos edades, o sea la de los ancianos y la de los niños, la autoridad de la Regla debe, sin embargo, mirar también por ellos. Téngase siempre presente 
propensión a la ira y a la violencia mediante la imagen del león, por ser éstos rasgos característicos de la naturaleza de este mamífero ${ }^{51}$.

No parecen ajustarse con exactitud a un ave concreta ninguna de las representadas en nuestra iglesia abacial en los capiteles 5oeste, 6oeste, 7este, 7oeste y 8este, aunque podía establecerse alguna conexión con el buitre o el águila. Respecto al origen y simbolismo del buitre, es este un animal asociado ya en la cultura del Antiguo Egipto a la maternidad divina, a un poder fecundador de la condición femenina como dador de vida equiparable al de la tierra madre y nutriz ${ }^{52}$, del cual se creía que "en su especie no hay unión sexual del macho y de la hembra, y que engendran sin acoplamiento" 53 . También fue tenido como símbolo de la abnegación paterna y materna, pues atribuían al buitre el instinto de alimentar con su propia sangre a sus polluelos si fuera preci$\mathrm{so}^{54}$, aunque lo cierto es que "no le dan sangre -como se dice por contaminación con la leyenda del pelícano- sino carne regurgitada" ${ }^{55}$. Su cualidad de carroñero le asocia a una labor purificadora que resulta más que adecuada para el pensamiento cristiano $\mathrm{y}$-aunque con frecuencia se le ha tenido como ave de mal agüero- ${ }^{56}$, lo cierto es que también ha gozado de buena consideración desde antiguo ${ }^{57}$. El Fisiólogo, al hablar del buitre, se centra más en las propiedades de la piedra eutocia ${ }^{58}$ que -supuestamente- se encontraba en el interior de su cabeza, y a la que se atribuían propiedades apotropaicas para la mujer durante el parto (de ahí su etimología, eû tokos). Su doble acepción maternal y virginal favoreció la equiparación del buitre con María Madre y Virgen, virgen por la partenogénesis (o gestación sin fecundación previa) a que hace referencia san Basilio, y madre por su equiparación terminológica en la escritura jeroglífica -tal y como demostró Horapolo en el siglo V-. Es incuestionable la importancia referencial de la Virgen en los cenobios cristianos (más evidente, si cabe, en el caso de los cistercienses), de ahí el valor simbólico del buitre como ejemplo de virginidad y ascesis para la progresión hacia la perfección monástica ${ }^{59}$. La labor pu-

su debilidad, y en modo alguno se aplique a ellos el rigor de la Regla en lo que a alimentos se refiere, sino que se les tendrá una amable consideración, y anticiparán las horas de comida regulares": Regla de San Benito, XXXVII.

${ }^{51}$ Cfr. RUIZ MONTEJO, Inés, "Del mito al símbolo cristiano: el claustro de Silos", en Anales de Historia del Arte, Volumen Extraordinario, septiembre 2010, pp. 125-148.

${ }_{52}$ Ibídem, p. 128.

${ }_{53}$ MARIÑO FERRO, Xosé Ramón, El simbolismo animal. Creencias y significados en la cultura occidental, Madrid, Encuentro, 1996, p. 54.

54 “Aquella fábula, en Occidente [...] fue traspasada al pelícano, del cual lo único que nos dicen los antiguos simbolistas y los autores de los Bestiarios es que devolvía la vida a sus retoños muertos regándolos con su sangre, pero no que los alimentase con ella": CHARBONNEAU-LASSAY, Louis (1996), op. cit., p. 458.

${ }_{55}$ MARIÑO FERRO, Xosé Ramón (1996), op. cit., p. 54.

56 "Donde está el cadáver, allí se juntan los buitres" (Mt. 24, 28).

${ }^{57}$ El mismo Plutarco dice en sus Vidas paralelas que "de todos los animales es el menos dañino, no tocando a nada de lo que los hombres siembran, plantan o apacientan, y alimentándose sólo de cuerpos muertos, porque se dice que no mata ni aún ofende a nada que tiene aliento": MARIÑO FERRO, Xosé Ramón (1996), op. cit., p. 52.

58 FISIÓLOGO, El bestiario, Madrid, 2002, cap. XXXII.

59 Cfr. RUIZ MONTEJO, Inés (2010), op. cit., pp. 128-131. 

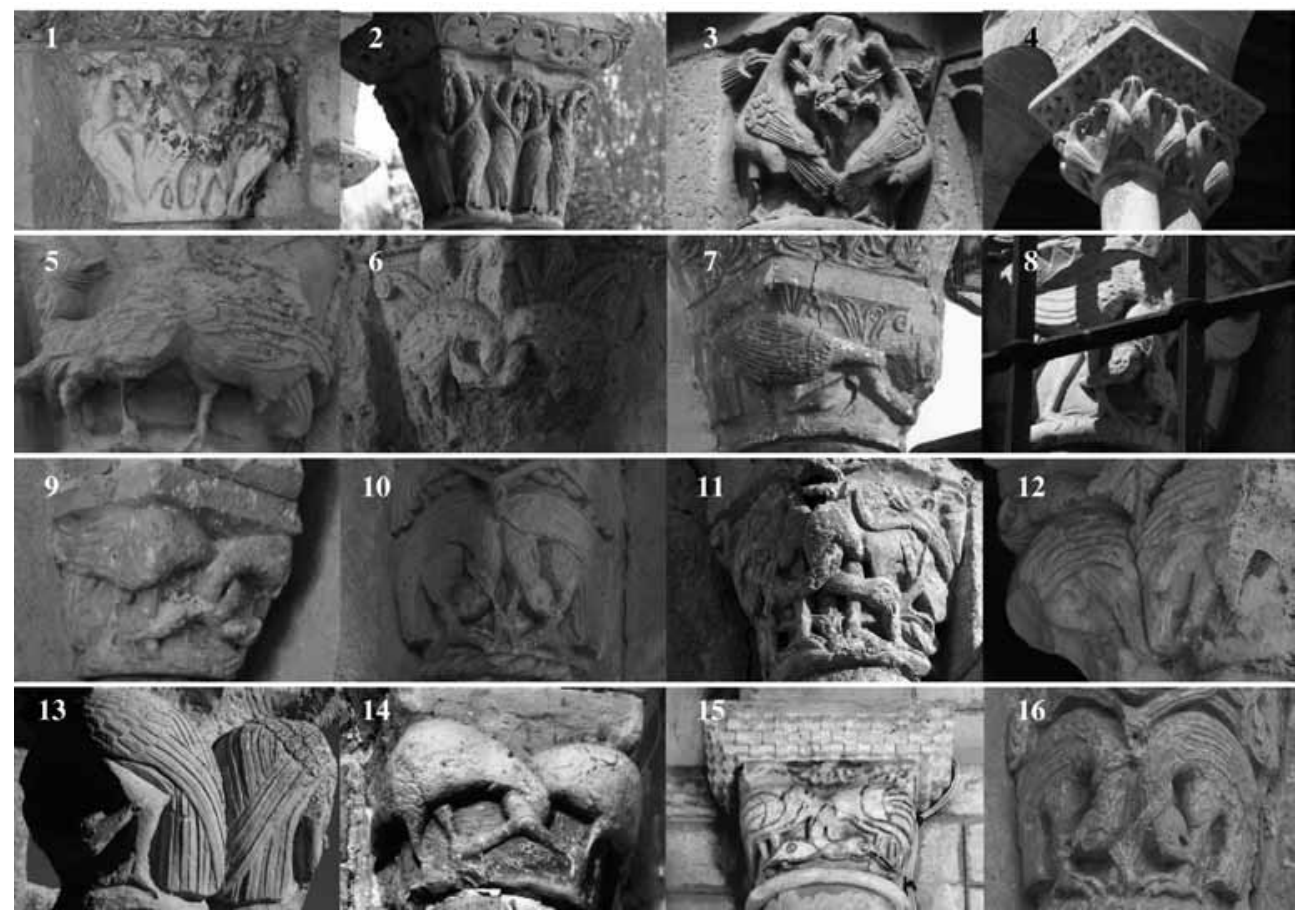

Fig. 3. Capiteles de aves individualizadas en posición axial, y de aves con cuellos entrelazados que se pican las patas, de diversas iglesias románicas segovianas.

rificadora atribuida al buitre puede identificarse con el gesto de picarse las patas, los muslos o incluso los cuellos (fotos 6 a 16, figura 3 ) por sus connotaciones positivas, al ser una representación fiel del expurgue que de forma frecuente realizan las aves para desproveerse de pulgas y piojos ${ }^{60}$.

En lo que al águila se refiere, es "rey de los (animales) que vuelan" ${ }^{\prime}$, y en razón de esa realeza se asemeja a Cristo al igual que el león, aunque también tiene una significación negativa por su rapacidad ${ }^{62}$. Los textos veterotestamentarios lo tienen por un animal abominable, al igual que otras aves ${ }^{63}$. Tomándolas del Antiguo Testamento se le

${ }^{60}$ En el claustro del monasterio de Santo Domingo de Silos encontramos buitres, pelícanos, caradrios y otros animales dotados de alas que adoptan actitudes de purga similares tales como picarse los artejos (=nudillos) o las alas, siendo la opción de Sierra una variante que conoció gran expansión en la zona.

${ }^{61}$ Cfr. DOCAMPO ÁLVAREZ, Pilar y VILLAR VIDAL, José Antonio (2003), op. cit., p. 110.

62 "De modo semejante, también son impuros tanto el león como el águila, y aquél es el rey de los animales salvajes y ésta de los que vuelan; en razón de la realeza, pues, se asemejan a Cristo, pero en razón de la rapacidad, al diablo": Ibídem, p. 110.

63 "He aquí entre las aves las que tendréis por abominación [...]: el águila, el quebrantahuesos y el halieto; el milano y el buitre según sus especies; toda clase de cuervos; el avestruz, la lechuza, el loro, la gaviota y el gavilán de toda clase; el búho, el mergo, el ibis; el cisne, el pelícano, el calamón; la garza, la cigüeña, en todas sus especies; la abubilla y el murciélago" (Lv. 11, 13-19). 
otorgan virtudes regeneradoras, pues según el rey salmista, Dios "sacia de bienes tus deseos, renueva tu juventud como la del águila" ${ }^{64}$, por ese motivo el Fisiólogo anima al hombre devoto a buscar la vida no perecedera, en el manantial bautismal de Cristo ${ }^{65}$.

Cerrando el repaso por los animales supuestamente representados en Sierra, en el capitel 7oeste aparecen dos pequeños mamíferos que podrían ser liebres o conejos. En lo que respecta a los lepóridos, se ha dicho que "los pequeños herbívoros, como la liebre, gozan de una bellísima reputación como alegoría de la fertilidad" 66 , aunque por su asombrosa fecundidad ${ }^{67}$ se asocian a la lascivia y a la lujuria, y por su actitud huidiza y desconfiada también son símbolo de la cobardía, de la timidez, y del temor. La conjunción águila-liebre, tiene su origen en las primitivas culturas orientales. Según los distintos autores esta conjunción iconográfica puede ser una simple representación de la naturaleza de estos animales, o perseguir un sentido alegórico y/o moralizante diverso ${ }^{68}$.

\section{Dentro y fuera de la Villa y Tierra de Pedraza ${ }^{69}$ : la itinerancia de un taller, la influencia de un modelo}

"Si la muerte devora al fénix, éste sin embargo permanece; la muerte podrá devorar mil, pero el fénix permanecerá así y todo. Este fénix es la forma común con que la naturaleza da de nuevo forma a los individuos y que se perdería por completo si no permitiera vivir a otro. Todos los seres del universo tienen el mismo privilegio: mientras subsista un ejemplar, su especie vivirá en él y la muerte nunca lo alcanzará..."

Jean de Meung, Le Roman de la Rose, segunda parte.

Santa María de la Sierra exhibe entre sus ruinas una curiosa colección de capiteles de temática animalística que la singulariza con respecto a otros templos castellanoleoneses de la Orden del Císter enclavados en el entorno del río Duero y que también

\footnotetext{
64 S1. 102, 5.

65 "El águila que tiene la naturaleza siguiente: cuando envejece, sus alas se vuelven pesadas y un velo nubla sus ojos; entonces busca un manantial de agua, y sobre ese manantial se eleva volando hacia lo alto hasta la atmósfera del sol, y allí prende fuego a sus alas y con los rayos del sol quema la telilla de los ojos; por último desciende hasta el manantial y se sumerge tres veces y al instante se renueva por completo de tal manera que resurge mucho mejor que antes en el vigor de las alas y la agudeza de la vista": DOCAMPO ÁLVAREZ, Pilar y VILLAR VIDAL, José Antonio (2003), op. cit., p. 112.

${ }_{66}$ MORALES MUÑIZ, Ma Dolores-Carmen, "El simbolismo animal en la cultura medieval”, en Espacio, tiempo y forma, serie III, Historia medieval, nº 9, 1996, p. 244.

67 "A la familia de de las liebres pertenecen los animales que en España llaman conejos; son de una fecundidad innumerable": PLINIO, VIII, 217 (81).

68 Cfr. MARTÍNEZ DE LAGOS, Eukene (1997), op. cit., pp. 319-326.

69 Las Comunidades de Ciudad y Tierra de Segovia y de Villa y Tierra de Ayllón, Coca, Cuéllar, Fresno de Cantespino, Fuentidueña, Haza, Iscar, Maderuelo, Montejo, Pedraza, Riaza y Sepúlveda fueron constituidas hacia mediados del siglo XII. Sotosalbos quedó incluida en la Comunidad de Segovia, mientras que Collado Hermoso (a cuyo término pertenece Santa María de la Sierra) lo fue de Pedraza. Cfr., MARTÍN POSTIGO, Ma de la Soterraña (1982), op. cit., p. 257.
} 


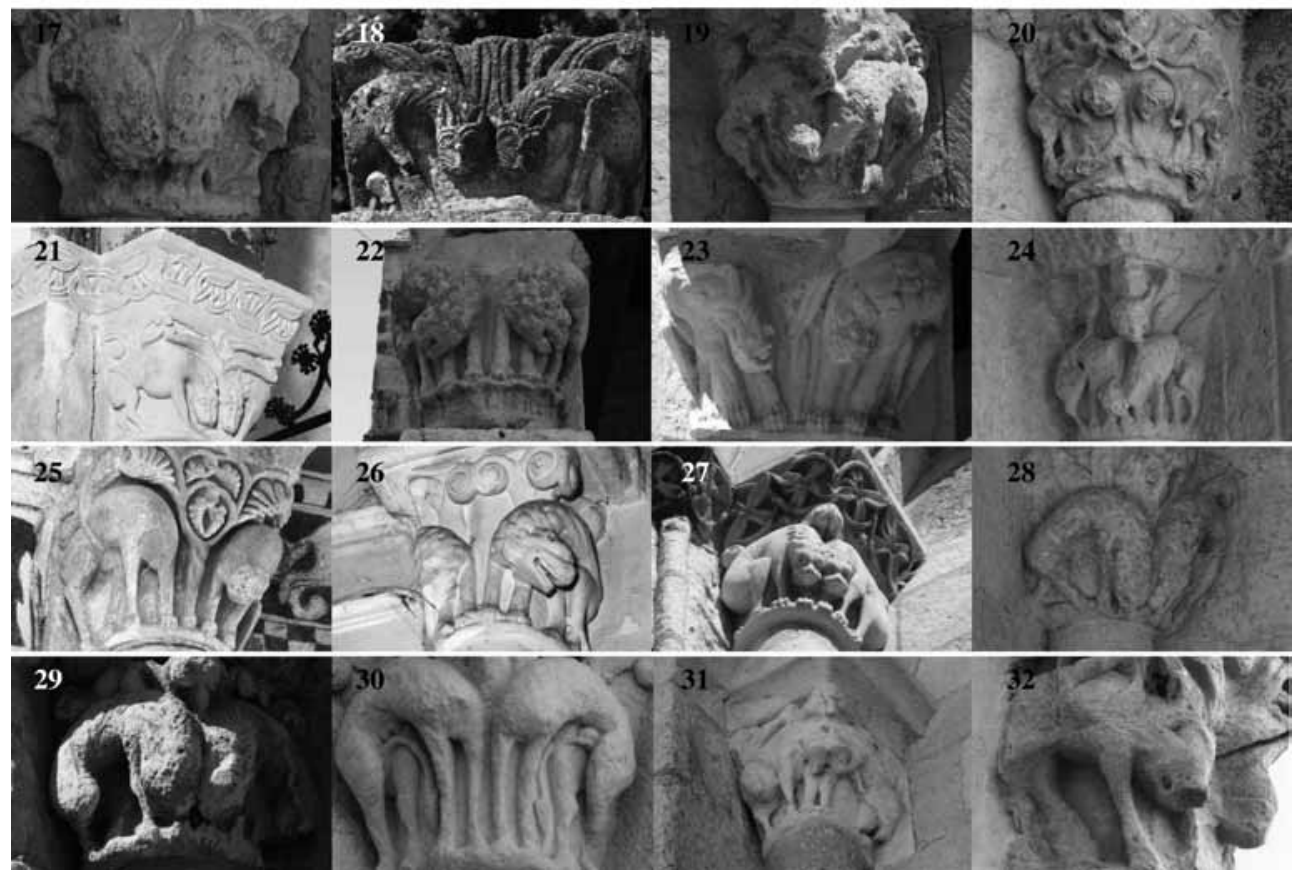

Fig. 4. Capiteles de leones patilargos afrontados, de diversas iglesias románicas segovianas.

han sido estudiados en profundidad desde el punto de vista ornamental ${ }^{70}(\mathrm{La}$ Espina, Matallana, Moreruela, Palazuelos, Sacramenia y Valbuena), evidenciando que no se encuentra ningún paralelismo decorativo con las opciones ornamentales empleadas en los capiteles de Santa María de la Sierra, a pesar de sumar casi cuatrocientos capiteles entre todas ellas. Tampoco se encuentra conexión temática alguna -en lo que a representación animalística se refiere- con el resto de monasterios bernardos de Castilla y León cuya decoración arquitectónica se inscribe en el arco cronológico 1140-1250, ni en Burgos (Santa María de Bujedo, Santa María la Real de Las Huelgas, Santa María de Rioseco y Santa María de Villamayor de los Montes), ni en León (Santa María de Carracedo, Santa María de Carrizo, Santa María de Gradefes y Santa María de Sandoval), ni en Palencia (San Andrés de Arroyo), ni en Soria (Santa María de Huerta) ${ }^{71}$. Por este motivo, la explicación a tales opciones ornamentales sólo se puede buscar en las obras del entorno y en la participación de artífices formados en talleres activos en la zona o que estuvieron directamente bajo la influencia de sus maestros más señalados.

Seguir la pista a los escultores que se dieron cita en Sierra requeriría de un ar-

70 Cfr. MONGE ZAPATA, M. Aitana, El repertorio ornamental medieval de las iglesias cistercienses del entorno del Duero, 2008 (trabajo inédito elaborado en el período de investigación del doctorado).

${ }^{71}$ Estos diez monasterios son los que, junto con los siete anteriores, son objeto de estudio de la tesis doctoral en la que me encuentro inmersa en estos momentos. 

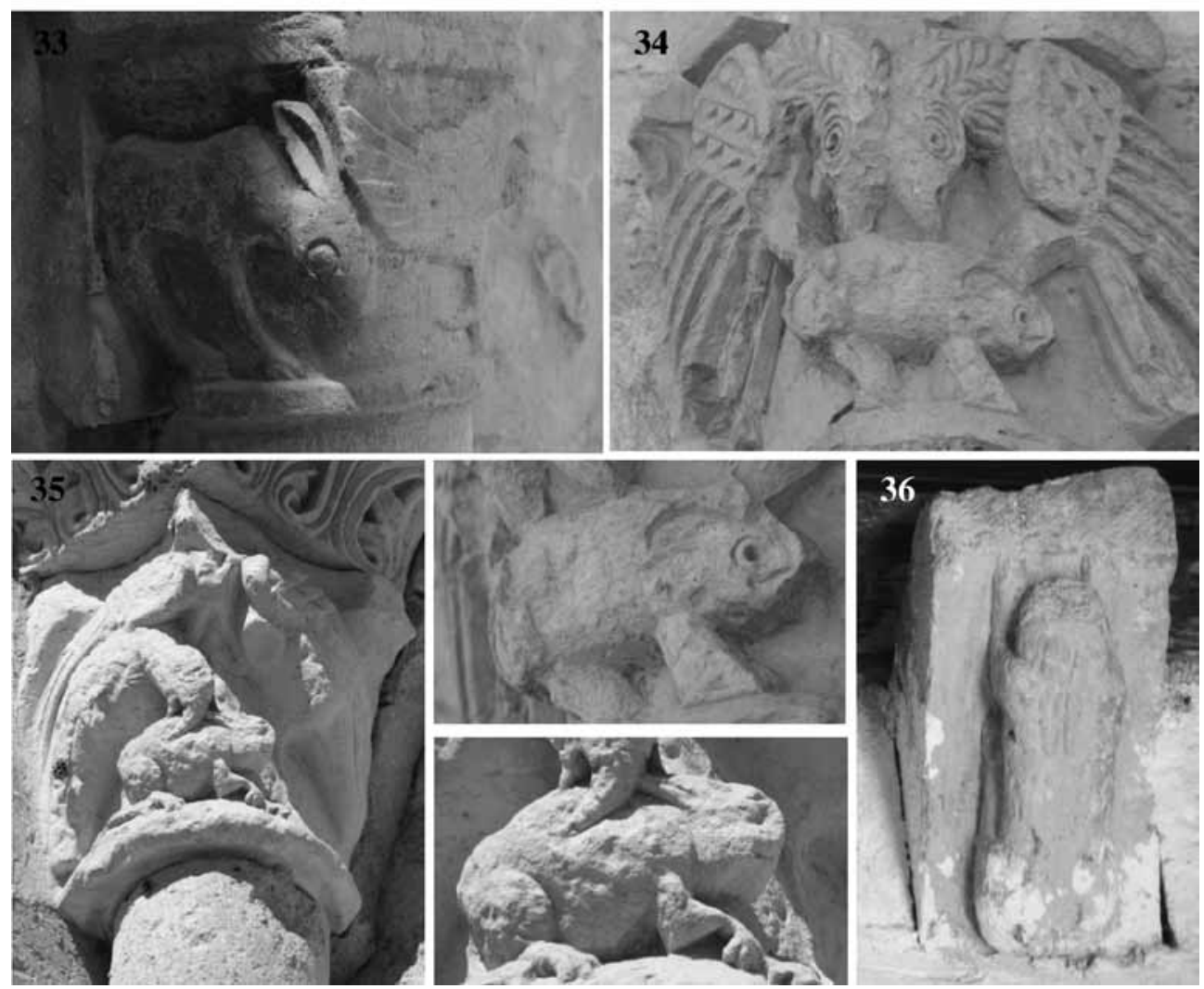

Fig. 5. Capiteles de aves rapaces con conejo o liebre, y canecillo de liebre, de diversas iglesias románicas segovianas.

tículo independiente, por esta razón aquí sólo se van a presentar algunas notas respecto al taller al que debieron pertenecer de una u otra forma, y de los principales ejemplos que se pueden encontrar dentro y fuera del entorno pedrazano.

Para comprender mejor la dinámica y procedimiento del románico rural, necesariamente hay que intentar localizar la iglesia “cabeza de taller". Una vez definido el templo principal, y para trazar la trayectoria del taller por la zona ${ }^{72}$, debe proseguirse con el seguimiento de la irradiación de pequeños talleres secundarios gestados a la sombra del principal $^{73}$, para poder llegar a observar el carácter continuista, arcaizante y decadente

72 Arquitectónicamente no suele tratarse de templos especialmente destacados, aunque en lo que a escultura se refiere la riqueza, variedad y calidad técnica hacen pensar que el maestro de obra realizase su aprendizaje junto a un artista de reputada fama, contando con la ayuda de un nutrido grupo de colaboradores que también quedan en la penumbra del anonimato histórico. Vid. RUIZ MONTEJO, Inés, "Concepto y método del románico rural", en Anales de Historia del Arte, nº 1, 1989, pp. 27-28.

73 Dos de las vías preferentes para la difusión del modo de obrar de un determinado taller son los cauces de los ríos y las vías de comunicación; en el caso que nos ocupa es más que evidente la eficaz difusión de modelos y la importancia de la ubicación del templo. Vid. n. 2. 
de unas formas difundidas -en función de la creciente demanda y del éxito del estilodebido a la escasez de medios y a la impericia de los artífices implicados.

Toda la provincia de Segovia está bajo la influencia del llamado "taller de Fuentidueña" en lo que a escultura monumental se refiere ${ }^{74}$. Esta escuela arranca en la iglesia de San Miguel de Fuentidueña (cabeza de taller y mejor ejemplo del mismo), en la cual debió participar un grupo de maestros "presumiblemente laicos, procedentes en su mayor parte del Monasterio de Silos o de su área de influencia" 75 . Los modelos del segundo taller silense fueron llevados de manos de las cuadrillas de artífices a múltiples destinos (entre ellos Fuentidueña), fosilizándose en el camino los modelos plásticamente consagrados hasta recrearse en fórmulas continuistas bajo la degradación formal y el conservadurismo plástico ${ }^{76}$. "Durante el segundo tercio del siglo XII - pero antes, habida cuenta de que la huella del Primer Taller no se rastrea más allá de Covarrubias-, la abadía de Santo Domingo de Silos supo protagonizar un impulso regenerador que se tradujo en una larga serie de epígonos dispuestos bajo la férula de su libro de modelos" "77, ya que la escasa competencia ejercida por otros focos productivos - como Cardeña o Arlanza- no fue capaz de hacer sombra a la de la abadía de Silos.

Los capiteles de Santa María de la Sierra son una imitación burda, retardataria y muy rudimentaria de otros que se pueden rastrear por multitud de templos románicos peninsulares, irradiados directamente del claustro silense, por la demanda creciente en distintos lugares de Castilla. Con total seguridad se puede afirmar que salieron de las manos de uno o varios artífices rurales y populares ${ }^{78}$, que -con sencillez y la mejor pericia que les fue posible- plasmaron con escasa capacidad técnica una iconografía vista directamente o transmitida por terceros.

74 Otros autores son de la opinión de que el punto de partida de esta escuela está en Pedraza y afirman que "hubo sin lugar a dudas una influencia mutua entre este templo cisterciense (de Santa María de la Sierra) y los románicos del medio rural; muchos de los logros, tanto de orden arquitectónico como decorativo, conseguidos por los constructores pedrazanos, hubieron de reflejarse en el templo monástico (véase como ejemplo uno de los dos únicos capiteles que hay en la iglesia del monasterio decorados con animales, y compárese con el de la iglesia de Las Vegas [...]; ambos esculpidos con dos felinos de lomos erizados [...]; el tema del segundo capitel (pareja de palomas), es también frecuente en el medio rural": SANTAMARÍA, Juan Manuel (1971), op. cit., p. 190 .

75 RUIZ MONTEJO, Inés, El románico de Villas y Tierras de Segovia, Madrid, Encuentro, 1988, p. 116.

76 "Los ecos de la escultura tardorrománica formulada en la abadía de Santo Domingo de Silos se prodigaron por [...] cerca de sesenta parroquias dispersas por las diócesis de Burgos, Osma, Segovia, Calahorra, Pamplona y Sigüenza. Claro está que sólo a un puñado de los edificios mencionados alcanzó el magisterio directo de los miembros del Segundo Taller de Silos. Será de la mano de los discípulos más aventajados [...] como se irá difundiendo el catálogo silense durante dos o tres generaciones. A finales del siglo XII la expansión rural de estos modelos llegará a su colapso, y los cinceles más populares e indoctos les someterán a una paulatina esclerosis": BOTO VARELA, Gerardo (2000), op. cit., p. 185.

77 Ibídem, p. 179. Algunos autores retrasan cronológicamente este influjo en la zona segoviana argumentando que "el trabajo del taller por Tierras de Segovia se desarrollaría en pleno siglo XIII, pudiéndose incluso extender hasta el siglo XIV en aquellas iglesias de factura más degenerada, aunque fieles en última instancia a fórmulas y directrices del taller”: RUIZ MONTEJO, Inés (1988), op. cit., p. 135.

78 Para apreciar mejor las diferencias y matices que ambas variantes del románico periférico presentan vid. RUIZ MONTEJO, Inés (1989), op. cit., pp. 21-37. 
La implantación de las opciones figurativas presentes en Santa María de la Sierra las encontramos en la provincia de Segovia en templos que distan de él desde sólo un par de leguas, hasta cuatro jornadas a pie ${ }^{79}$.

Durante el trabajo de campo (sistemáticamente llevado a cabo en la primavera del año 2010 con la ayuda inestimable del también historiador del arte José Rufino Novo), fueron rastreados en la provincia de Segovia numerosos elementos ornamentales de naturaleza animalística similares a los anteriormente analizados en la iglesia de Sierra ${ }^{80}$.

Debido a su elevado número -y para una más fácil visualización de estos elementos catalogados- el sistema elegido para su presentación es una tabla en la que sólo se deja constancia del templo en que se encuentran, de la localidad en que está enclavado este y del número de fotografía según el presente artículo:

\begin{tabular}{|l|l|c|}
\hline \multicolumn{2}{|c|}{ AVES ACULADAS O AFRONTADAS EN POSICIÓN AXIAL } \\
\hline \multicolumn{1}{|c|}{ ADVOCACIÓN DEL TEMPLO } & \multicolumn{1}{|c|}{ LOCALIDAD } & FOTOGRAFÍA N \\
\hline Asunción de Nuestra Señora & Duratón & 1 y 2 \\
\hline Nuestra Señora de las Nieves & Rebollo & 3 \\
\hline San Sebastián & San Pedro de Gaíllos & -- \\
\hline San Martín & Segovia & 4 \\
\hline Santísima Trinidad & Segovia & -- \\
\hline San Miguel Arcángel & Languilla & -- \\
\hline Inmaculada Concepción & Navas de Riofrío & -- \\
\hline Nuestra Señora de la Octava & Peñarrubias de Pirón & 5 \\
\hline San Bartolomé & Sepúlveda & -- \\
\hline Natividad de Nuestra Señora & Sotillo & -- \\
\hline San Miguel Arcángel & Turégano & -- \\
\hline Nuestra Señora de la Natividad & Valdesimonte & -- \\
\hline
\end{tabular}

79 Distancias aproximadas -a través de las actuales vías de comunicación- entre Collado Hermoso y los templos con elementos figurativos similares a los presentes en Sierra: Aldeasoña (100 km.), Ayllón (73 km.), Basardilla (14 km.), Becerril (70 km.), Caballar (13 km.), Castiltierra (70 km.), Castroserracín (75 km.), Cerezo de Abajo (40 km.), Duratón (55 km.), Fuentemizarra (71 km.), Fuentesoto (59 km.), Fuentidueña (57 km.), Languilla (78 km.), Navas de Riofrío (34 km.), Orejana (29 km.), Ortigosa del Monte (41 km.), Pecharromán (63 km.), Peñarrubias de Pirón (39 km.), Perorrubio (48 km.), Rebollo (22 km.), Requijada (11 km.), San Pedro de Gaíllos (26 km.), Santo Domingo de Pirón (13 km.), Segovia (22 km.), Sepúlveda (65 km.), Sequera de Fresno (65 km.), Siguero (33 km.), Sotillo (38 km.), Turégano (18 km.), Valdesimonte $(36 \mathrm{~km}$.) y Vivar de Fuentidueña (63 Km.).

${ }^{80}$ Se prevé la publicación de otro artículo que sea la continuación del presente, un estudio que estará dedicado a profundizar en cuestiones que aquí sólo se plantean de forma muy sintética y resumida, para intentar establecer la participación de diversos talleres, la utilización de determinados modelos, las influencias externas, y las variantes iconográficas entre otras cosas. 


\begin{tabular}{|l|l|c|}
\hline \multicolumn{2}{|c|}{ AVES PICÁNDOSE LAS PATAS CON LOS CUELLOS ENTRELAZADOS } \\
\hline \multicolumn{1}{|c|}{ ADVOCACIÓN DEL TEMPLO } & \multicolumn{1}{|c|}{ LOCALIDAD } & FOTOGRAFÍA N ${ }^{\circ}$ \\
\hline San Miguel Arcángel & Ayllón & 6 \\
\hline Asunción de Nuestra Señora & Becerril & 7 \\
\hline Santo Cristo Corporario & Castiltierra & 8 \\
\hline Nuestra Señora del Ejido & Fuentemizarra & 9 \\
\hline San Vicente Mártir & Fuentesoto & -- \\
\hline San Miguel Arcángel & Fuentidueña & 10 \\
\hline San Andrés & Pecharromán & 11 \\
\hline San Pedro ad Víncula & Perorrubio & 12 \\
\hline Nuestra Señora de las Vegas & Requijada & 13 \\
\hline Nuestra Señora de la Peña & Sepúlveda & 14 \\
\hline Natividad de Nuestra Señora & Sotillo & 15 \\
\hline Santa María Magdalena & Vivar de Fuentidueña & 16 \\
\hline
\end{tabular}

\begin{tabular}{|l|l|c|}
\hline \multicolumn{2}{|c|}{ LEONES PATILARGOS } \\
\hline \multicolumn{1}{|c|}{ ADVOCACIÓN DEL TEMPLO } & \multicolumn{1}{|c|}{ FOTOGIDAD } & -- \\
\hline Santa María Magdalena & Aldeasoña & 17 \\
\hline San Miguel Arcángel & Ayllón & 18 \\
\hline San Nicolás & Ayllón & 19 \\
\hline San Bartolomé & Basardilla & 20 \\
\hline Asunción de Nuestra señora & Caballar & 21 \\
\hline Santo Cristo Corporario & Castiltierra & -- \\
\hline Nuestra Señora de la Asunción & Duratón & -- \\
\hline San Miguel Arcángel & Fuentidueña & 22 \\
\hline Santa María la Mayor & Fuentidueña & 23 \\
\hline San Juan Bautista & Orejana & -- \\
\hline San Julián & Ortigosa del Monte & -- \\
\hline San Pedro ad Víncula & Perorrubio & 24 y 25 \\
\hline Nuestra Señora de las Vegas & Requijada & -- \\
\hline Santo Domingo de Silos & Santo Domingo de Pirón & 26 y 27 \\
\hline San Esteban & Segovia & -- \\
\hline San Martín & Segovia & 28 \\
\hline San Millán & Segovia & 30 y 31 \\
\hline San Quirce & Segovia & \\
\hline Santísima Trinidad & Segovia & \\
\hline
\end{tabular}




\begin{tabular}{|l|l|c|}
\hline Asunción de Nuestra Señora & Sequera de Fresno & -- \\
\hline Nuestra Señora de Vargas & Siguero & 32 \\
\hline San Miguel Arcángel & Turégano & -- \\
\hline
\end{tabular}

\begin{tabular}{|l|l|c|}
\hline \multicolumn{2}{|c|}{ RAPACES CON LIEBRES } \\
\hline \multicolumn{1}{|c|}{ ADVOCACIÓN DEL TEMPLO } & \multicolumn{1}{|c|}{ LOCALIDAD } & FOTOGRAFÍA N $^{\circ}$ \\
\hline Santo Tomás & Castroserracín & 33 \\
\hline San Román Abad & Cerezo de Abajo & 34 \\
\hline Asunción de Nuestra Señora & Sequera de Fresno & 35 \\
\hline
\end{tabular}

\begin{tabular}{|l|l|c|}
\hline \multicolumn{3}{|c|}{ LIEBRE } \\
\hline \multicolumn{1}{|c|}{ ADVOCACIÓN DEL TEMPLO } & \multicolumn{1}{|c|}{ LOCALIDAD } & FOTOGRAFÍA N $^{\circ}$ \\
\hline Nuestra Señora de la Asunción & Losana del Pirón & 36 \\
\hline
\end{tabular}

Muchas cosas han quedado sin decir, muchas conclusiones sin apuntalar, muchos matices sin explicar, muchas cuestiones sin aclarar... A pesar de todo, creo que sí que se ha alcanzado el principal objetivo perseguido con este artículo: evidenciar la singularidad ornamental de los capiteles de la iglesia cisterciense segoviana de Santa María de la Sierra, y ponerla en paralelo con otras de su Orden, con otras de su entorno, y con otras de Castilla y León, a fin de presentar unas primeras conclusiones y dejar abiertas otras sendas para posteriores investigaciones que se irán acometiendo. 